\title{
Detection, Identification, and Characterization of Phytoplasmas Infecting Apple and Pear Trees in Belarus
}

N. Valasevich, Julius Kühn Institute, Federal Research Centre for Cultivated Plants, Institute for Plant Protection in Fruit Crops and Viticulture, Schwabenheimerstrasse 101, 69221 Dossenheim, Germany, and Department of Biotechnology, Institute for Fruit Growing, Kovaleva 2, 223013 Samochvalovichi, Belarus; and B. Schneider, Julius Kühn Institute, Federal Research Centre for Cultivated Plants, Institute for Plant Protection in Fruit Crops and Viticulture, Schwabenheimerstrasse 101, 69221 Dossenheim, Germany

\begin{abstract}
Valasevich, N., and Schneider, B. 2016. Detection, identification, and characterization of phytoplasmas infecting apple and pear trees in Belarus. Plant Dis. 100:2275-2280.

In Samochvalovichi, Belarus, apple and pear tree root samples were examined for the presence of phytoplasmas using a universal $16 \mathrm{~S}$ rDNA-based PCR assay. Out of 27 tested apple trees, 23 were found to be infected by 'Candidatus Phytoplasma mali' and 46 out of 58 pear trees were positive for the presence of ' $\mathrm{Ca}$. P. pyri.' Species were identified by sequence analysis of the $16 \mathrm{~S}$ rDNA amplicons. The molecular diversity of the phytoplasma isolates was examined by analysis of an $h f l B$ gene using single-strand conformation polymorphism (SSCP) and sequence analysis. Therefore $h f l B$ gene amplicons from ' $\mathrm{C} a$. P. mali' and ' $\mathrm{Ca}$. P. pyri' accessions were cloned

after amplification. Screening of 640 cloned $h f l B$ fragments by SSCP analysis revealed the presence of eight different profiles for ' $C a$. P. mali' and 12 different profiles for ' $\mathrm{Ca}$. P. pyri.' The variants were sequenced and compared in multiple alignments. The nucleic acid homology among the $h f l B$ gene fragments ranged between 95.4 and $100.0 \%$ and 81.3 to $100.0 \%$ for ' $C a$. P. mali' and ' $C a$. P. pyri,' respectively, indicating a high genetic variability within the species. This is the first report on the occurrence of ' $\mathrm{Ca}$. P. mali' and ' $\mathrm{Ca}$. P. pyri' in Belarusian apple and pear trees and their molecular diversity.
\end{abstract}

Phytoplasmas are bacterial plant pathogens of the class Mollicutes that cause significant losses in agricultural production worldwide (Bertaccini and Duduk 2009). They are wall-less, nonhelical prokaryotes that derived from gram-positive bacteria and are transmitted by phloem-feeding homopterous insects and classified in the provisional genus 'Candidatus Phytoplasma' (IRPCM 2004). Over 30 species are recognized within the genus ' $\mathrm{Ca}$. Phytoplasma' and the number is growing. Despite their wide distribution and their presence in more than a thousand plant species (Lee et al. 2000), the information about phytoplasmas in Belarus is very limited, whereas phytoplasma diseases of different crops have been described for the neighboring countries (Cieślińska and Kruczyńska 2014; Cieślińska and Morgas 2011; Girsova et al. 2008; Jomantiene et al. 2011; Valiunas 2003). The only publication related to phytoplasma diseases of fruit and berry crops in Belarus is a monograph of Kukharchik (2012), where a description of hypothetically present but unreported phytoplasma diseases is given.

Among the phytoplasma diseases occurring in Europe, pome fruit phytoplasmoses are of particular importance. They are caused by closely related species belonging to the apple proliferation group and comprise ' $C a$. P. mali' (AP) and $C a$. P. pyri' (PD) in apple and pear, respectively (Seemüller and Schneider 2004). Although ' $\mathrm{Ca}$. P. mali' and ' $\mathrm{Ca}$. P. pyri' are EPPO-listed quarantine pests responsible for major economic losses in Europe (Bertaccini and Duduk 2009; Lee et al. 2000; Mehle et al. 2010; Seemüller and

Corresponding author: N. Valasevich,

E-mail: natallia.valasevich@julius-kuehn.de

Nucleotide sequence data for the fragments of $h f l B$ gene ATP00464 is available in the GenBank and EMBL databases under accession numbers LT548594 to LT548613.

Accepted for publication 20 June 2016.

http://dx.doi.org/10.1094/PDIS-04-16-0498-RE

This article is in the public domain and not copyrightable. It may be freely reprinted with customary crediting of the source. The American Phytopathological Society, 2016.
Schneider 2004), their presence in pome fruit crops in Belarus has never been investigated.

Phytoplasma titers in roots of pome trees are generally higher than in aerial parts and roots are, unlike the stem, colonized throughout the year, which renders this plant tissue most suited for the detection of the pathogens (Seemüller et al. 1984). The most utilized technique for the detection of phytoplasmas is PCR with either general or group specific primers targeting the conserved $16 \mathrm{~S}$ ribosomal genes of the pathogens. In many cases, nested PCR is performed due to low titers of phytoplasmas in plants (Ahrens and Seemüller 1992; Delic 2012; Gundersen and Lee 1996; Lee et al. 1994). The high level of 16 S rDNA sequence identity within phytoplasma species, which is an advantage for general phytoplasma detection, is however a disadvantage for strain differentiation within a species. Characterizing the pathogens beyond species level is necessary to distinguish virulent from nonvirulent strains. This has been clearly shown for ' $\mathrm{Ca}$. P. mali,' where sequence differences of less conserved genes could be linked to pathological characteristics of strains (Seemüller et al. 2013). A number of less conserved genes like imp, aceF, pnp, secY, and the $h f l B$ gene have been identified, revealing a higher diversity that can be used for intraspecific typing (Danet et al. 2007; Schneider and Seemüller 2009). One approach for phytoplasma strain differentiation is single-strand conformation polymorphism (SSCP) analysis. This method has the potential to reveal subtle differences between PCR amplified fragments undetected by routine restriction fragment length polymorphism (RFLP) analysis (Delic 2012). SSCP analysis is based on the electrophoretic separation of single-stranded nucleic acids forming a different secondary structure leading to measurable differences in gel mobility (Musić et al. 2008; Schneider and Seemüller 2009; Seemüller et al. 2011b).

In the present study, an $h f l B$ (synonym $f t s H$ ) gene fragment was selected to study the heterogeneity of apple and pear tree phytoplasmas in Belarus. The amplified fragment is homologous to the location ATP00464 of ' $C a$. P. mali' strain AT (accession no. CU469464) and has been previously used in SSCP and sequence analyses for differentiation of ' $\mathrm{Ca}$. P. mali' strains. In combination with the disease history of individual trees the sequence data were also used for assessment of strain virulence in singly and multiply infected apple trees (Seemüller et al. 2011b). 
The study was initiated since there was no information on the presence and genetic variability of pome fruit phytoplasmas in Belarus.

\section{Materials and Methods}

Plant material. During the autumn of 2014 and spring of 2015, roots from 27 apple (Malus domestica) and 58 pear (Pyrus communis) trees were collected. Pear samples were obtained from plants growing in the collection orchard of the Institute for Fruit Growing (Samochvalovichi), while apple roots were sampled from old trees growing in private orchards in the same area. ' $C a$. P. mali' and ' $\mathrm{Ca}$. P. pyri' accessions maintained in Catharanthus roseus, as well as healthy apple and pear plants from the collection of the Institute for Plant Protection in Fruit Crops and Viticulture, Dossenheim, Germany, were used as positive and negative controls, respectively.
DNA extraction. Total DNA was extracted from $0.3 \mathrm{~g}$ of phloem tissue collected from fresh roots by the CTAB extraction method (Ahrens and Seemüller 1992). DNA pellets were resuspended in $50 \mu \mathrm{l}$ of sterile water and store at $-20^{\circ} \mathrm{C}$ until use.

PCR amplification. The DNA extracts were subjected to PCR with phytoplasma-universal primer pair P1 (5'-AAGAGTTTGATCCTG GCTCAGGATT-3')/tint (5'-TCAGGCGTGTGCTCTAACCAGC-3') specific to the $5^{\prime}$ end of the 16S rRNA gene and the t-RNAile gene in the 16S-23S rRNA spacer region (Lorenz et al. 1995; Smart et al. 1996). After first round PCR, a 1/30 dilution of the amplicons was used as template for nested PCR with the fruit tree specific primer pair fO1 (5'-CGGAAACTTTTAGTTTCAGT-3')/rO1 (5'-AAGTGCCCAACT AAATGAT-3') (Lorenz et al. 1995). The parameters for amplification in the first round and second round were as following: initial denaturation at $95^{\circ} \mathrm{C}$ for $5 \mathrm{~min}$ followed by 35 cycles at $95^{\circ} \mathrm{C}$ for $30 \mathrm{~s}, 55^{\circ} \mathrm{C}$

Table 1. Isolate abbreviation, host, and accession numbers of $h f l B$ gene sequences

\begin{tabular}{|c|c|c|c|c|}
\hline Species & Strain & Host & SSCP profile & Accession no. (hflB gene) \\
\hline Ca. P. mali & AP1 & Malus domestica Borkh. & A & \\
\hline Ca. P. mali & AP15-44 & Malus domestica Borkh. & A & LT548594 \\
\hline Ca. P. mali & AP19-11 & Malus domestica Borkh. & $\mathrm{B}$ & LT548595 \\
\hline Ca. P. mali & AP4 & Malus domestica Borkh. & $\mathrm{C}$ & \\
\hline Ca. P. mali & AP7 & Malus domestica Borkh. & $\mathrm{C}$ & \\
\hline Ca. P. mali & AP9 & Malus domestica Borkh. & $\mathrm{C}$ & \\
\hline Ca. P. mali & AP16 & Malus domestica Borkh. & $\mathrm{C}$ & \\
\hline Ca. P. mali & AP23 & Malus domestica Borkh. & $\mathrm{C}$ & \\
\hline Ca. P. mali & AP27 & Malus domestica Borkh. & $\mathrm{C}$ & LT548596 \\
\hline Ca. P. mali & AP15-37 & Malus domestica Borkh. & $\mathrm{D}$ & LT548597 \\
\hline Ca. P. mali & AP14-46 & Malus domestica Borkh. & $\mathrm{E}$ & LT548598 \\
\hline Ca. P. mali & AP14-44 & Malus domestica Borkh. & $\mathrm{F}$ & LT548599 \\
\hline Ca. P. mali & AP14-45 & Malus domestica Borkh. & $\mathrm{G}$ & LT548600 \\
\hline Ca. P. mali & AP17 & Malus domestica Borkh. & $\mathrm{H}$ & LT548601 \\
\hline Ca. P. mali & AP18 & Malus domestica Borkh. & $\mathrm{H}$ & \\
\hline Ca. P. mali & AP19-23 & Malus domestica Borkh. & $\mathrm{H}$ & \\
\hline Ca. P. pyri & PD1-1 & Pyrus communis L. & $\mathrm{A}$ & \\
\hline Ca. P. pyri & PD1 & Pyrus communis $\mathrm{L}$. & $\mathrm{A}$ & \\
\hline Ca. P. pyri & PD2 & Pyrus communis L. & $\mathrm{A}$ & \\
\hline Ca. P. pyri & PD3 & Pyrus communis L. & A & \\
\hline Ca. P. pyri & PD4 & Pyrus communis L. & A & \\
\hline Ca. P. pyri & PD5 & Pyrus communis L. & A & \\
\hline Ca. P. pyri & $3 \mathrm{PD}$ & Pyrus communis $\mathrm{L}$. & $\mathrm{A}$ & LT548602 \\
\hline Ca. P. pyri & $8 \mathrm{PD}$ & Pyrus communis L. & $\mathrm{A}$ & \\
\hline Ca. P. pyri & $11 \mathrm{PD}$ & Pyrus communis L. & $\mathrm{A}$ & \\
\hline Ca. P. pyri & $13 \mathrm{PD}$ & Pyrus communis L. & A & \\
\hline Ca. P. pyri & $16 \mathrm{PD}$ & Pyrus communis L. & A & \\
\hline Ca. P. pyri & $17 \mathrm{PD}$ & Pyrus communis L. & A & \\
\hline Ca. P. pyri & $18 \mathrm{PD}$ & Pyrus communis L. & A & \\
\hline Ca. P. pyri & 20PD & Pyrus communis $\mathrm{L}$. & $\mathrm{A}$ & \\
\hline Ca. P. pyri & $23 \mathrm{PD}$ & Pyrus communis L. & $\mathrm{A}$ & \\
\hline Ca. P. pyri & 24PD & Pyrus communis L. & A & \\
\hline Ca. P. pyri & 26PD & Pyrus communis L. & A & \\
\hline Ca. P. pyri & 29PD & Pyrus communis L. & A & \\
\hline Ca. P. pyri & $34 \mathrm{PD}$ & Pyrus communis $\mathrm{L}$. & A & \\
\hline Ca. P. pyri & 3PD-3 & Pyrus communis L. & $\mathrm{B}$ & \\
\hline Ca. P. pyri & 11PD-10 & Pyrus communis L. & $\mathrm{B}$ & LT548612 \\
\hline Ca. P. pyri & 18PD-20 & Pyrus communis L. & B & \\
\hline Ca. P. pyri & 20PD-15 & Pyrus communis L. & $\mathrm{B}$ & \\
\hline Ca. P. pyri & $24 \mathrm{PD}-4$ & Pyrus communis L. & $\mathrm{B}$ & \\
\hline Ca. P. pyri & 26PD-9 & Pyrus communis L. & B & \\
\hline Ca. P. pyri & 17PD-7 & Pyrus communis L. & $\mathrm{C}$ & LT548610 \\
\hline Ca. P. pyri & PD4-5.2 & Pyrus communis L. & $\mathrm{D}$ & LT548603 \\
\hline Ca. P. pyri & PD7-7.2 & Pyrus communis L. & $\mathrm{E}$ & LT548611 \\
\hline Ca. P. pyri & PD7 & Pyrus communis L. & $\mathrm{F}$ & LT548604 \\
\hline Ca. P. pyri & PD7-7.27 & Pyrus communis $\mathrm{L}$. & $\mathrm{G}$ & LT548605 \\
\hline Ca. P. pyri & 8PD-27 & Pyrus communis $\mathrm{L}$. & $\mathrm{H}$ & LT548607 \\
\hline Ca. P. pyri & 34PD-12 & Pyrus communis L. & I & LT548609 \\
\hline Ca. P. pyri & $34 \mathrm{PD}-2$ & Pyrus communis L. & $\mathrm{J}$ & LT548608 \\
\hline Ca. P. pyri & 23PD-6 & Pyrus communis L. & $\mathrm{K}$ & LT548613 \\
\hline Ca. P. pyri & 13PD-17 & Pyrus communis L. & $\mathrm{L}$ & LT548606 \\
\hline
\end{tabular}


for $30 \mathrm{~s}$, and $72^{\circ} \mathrm{C}$ for $1.5 \mathrm{~min}(\mathrm{P} 1 /$ tint $)$ or $1 \mathrm{~min}$ (fO1/rO1). A final step of $72^{\circ} \mathrm{C}$ for 5 min was performed.

For amplification of the $h f l B$ gene fragments from ' $C a$. P. mali' and ' $\mathrm{Ca}$. P. pyri,' the primer pairs fhflB3_1 (5'-TTCTAGCTATT CATCGTGAA-3')/rhflB3 (5'-CGGCGCGATTAGTAGCTCC-3') (Schneider and Seemüller 2009) and fhflB_PD (5'-TCCATTTCGG TTAAAAGTTG-3')/rhflB_PD (5'-TGATTTTTTAAAACAACCAC-3') (this study), respectively, were used. The parameters for amplification were as following: initial denaturation at $95^{\circ} \mathrm{C}$ for 5 min followed by 35 cycles at $95^{\circ} \mathrm{C}$ for $30 \mathrm{~s}, 50^{\circ} \mathrm{C}$ for $30 \mathrm{~s}$, and $72^{\circ} \mathrm{C}$ for $30 \mathrm{~s}$. A final step of $72^{\circ} \mathrm{C}$ for 5 min was performed.

Amplification was performed with FastGene Taq DNA polymerase (NIPPON Genetics EUROPE, Germany) in a thermocycler iCycler (Bio-Rad, U.S.A.). The presence of PCR products was verified on a UV transilluminator after $1 \%$ agarose gel electrophoresis and ethidium bromide staining.

Cloning. The PCR fragments of the $h f l B$ gene from ' $\mathrm{Ca}$. P. mali' (12 amplicons) and 'Ca. P. pyri' (20 amplicons) were purified by QIAquick PCR purification kit (Qiagen, Germany) and ligated in pGEM-T (Promega, U.S.A.). The constructs were transformed into Escherichia coli XL1 blue cells (Stratagene, U.S.A.) and plated on Luria-Bertani broth containing $1 \mathrm{mM}$ IPTG, $100 \mu \mathrm{g} \mathrm{ml}^{-1}$ ampicillin, and $40 \mu \mathrm{g} \mathrm{ml}^{-1} \mathrm{X}$-gal, $1 \%$ agar.

SSCP analysis. The presence of specific inserts was tested in clones of all ligation reactions by colony-PCR using gene specific primers, and 20 PCR fragments per ligation reactions were selected. The PCR fragments were heat-denatured and the single-stranded fragments separated in a $10 \%$ polyacrylamide gel at $25 \mathrm{~V} / \mathrm{cm}$ for $5 \mathrm{~h}$ at $4^{\circ} \mathrm{C}$ in $1 \times \mathrm{TBE}$ buffer. In case of pear decline amplicons, the electrophoresis was performed for $4 \mathrm{~h}$ due to a difference in PCR product length. Visualization of DNA bands was done by silver staining (Schneider and Seemüller 2009).

Sequence analysis. Species identification was performed by sequence analysis of the nested 16S rDNA amplicons using the primers fO1 and rO1. Plasmids carrying representative $h f l B$ gene fragments showing different SSCP profiles were isolated from recombinant $E$. coli colonies using QIAprep Spin Miniprep Kit (Qiagen, Germany) and sequenced (Eurofins, Germany) with M13 forward and reverse primers.

Nucleotide sequence data for the fragments of $h f l B$ gene fragment (ATP00464 homologs) were submitted to the GenBank and EMBL databases under accession numbers LT548594 to LT548613. When samples shared identical sequences, only one sequence was submitted to the database (Table 1).

Sequences were analyzed using MEGA 6.0 program package (Tamura et al. 2013). The Clustal W algorithm was used for multiple alignments of the sequences. Genetic relationship of phytoplasma isolates was investigated by sequence comparison with isolates available in EMBL/GenBank databases. Phylogenetic trees were built by the maximum likelihood model. Bootstrap analysis with 1,000 replicates was performed to test the robustness of the internal branches.

\section{Results}

Disease symptoms, pathogen detection, and identification. Studies on phytoplasmas infecting pome crops in Belarus started in autumn 2014 when a number of pear trees showed early foliar reddening and premature defoliation. Obvious symptoms of apple proliferation disease caused by ' $\mathrm{Ca}$. P. mali' such as witches'-brooms, undersized fruits, enlarged stipules, and growth suppression were not observed on the over 30-year-old apple trees.

From the 27 apple trees, 23 were found to be phytoplasmapositive. Of the 58 pear tree samples, 46 trees revealed a phytoplasma infection. The fO1/rO1 amplicons were sequenced and species identified by comparison with $16 \mathrm{~S}$ rDNA sequences of reference phytoplasmas in GenBank/EMBL databases. The analysis confirmed that apple and pear trees were infected by ' $\mathrm{Ca}$. P. mali' and ' $\mathrm{Ca}$. P. pyri,' respectively. No sequence differences were observed among the AP amplicons. The same applied for the PD fO1/rO1 products.

For further molecular characterization, 12 samples from apple trees and 20 samples from pear trees were selected that showed strong amplification products after PCR with group-specific primers fO1/rO1. The amplification of the $h f l B$ gene with the primers fhflB3_1/rhflB3 and
fhflB_PD/rhflB_PD resulted in fragments of the expected size of $528 \mathrm{bp}$ and $345 \mathrm{bp}$ for AP and PD, respectively. The fhflB3_1/rhflB3 primer pair used for amplification of the ' $C a$. P. mali' $h f l B$ gene did not always amplify the gene from all ' $\mathrm{Ca}$. P. pyri' accessions. Therefore, the internal highly conserved primers fhflB_PD/rhflB_PD were selected, which amplified a $345 \mathrm{bp}$ fragment from all accessions.

Cloning and SSCP analyses. $H f l B$ gene amplicons from 12 apple and 20 Belarusian pear tree accessions were cloned and inserts of 20 positive clones per accession were subjected to SSCP analysis. The analyses of the $h f l B$ gene fragments revealed the presence of eight different profiles for apple proliferation phytoplasmas within 240 clones tested (Fig. 1A). A list of the SSCP accessions revealed is reported in Table 1. The single stranded DNA molecules typically formed one to two bands after denaturation in formamide buffer. Nine AP accessions showed a homogeneous pattern of all 20 fragments with three different profiles designated A, C, and H. Two accessions showed a high frequency of either profile A or $\mathrm{H}$ accompanied by strains represented by profiles $\mathrm{D}$ and $\mathrm{B}$. One accession showed three different profiles designated E, F, and G not present in the other accessions. Profile $\mathrm{C}$ was dominant and observed in half of the tested accessions and in half of the screened AP clones. The profiles $\mathrm{H}, \mathrm{A}$, and $\mathrm{F}$ occurred less frequently and were observed in 24,16 , and $7.5 \%$, respectively, of AP clones examined. Profile B was present twice and the profiles D, E, and G were present once.

In the 400 ' $\mathrm{Ca}$. P. pyri' fragments tested, 12 different profiles were observed with up to three ssDNA bands (Fig. 1B). One SSCP profile dominated and was observed in 19 of the 20 accessions tested and in 355 out of 400 clones examined and designated profile $\mathrm{A}$. The remaining 11 profiles were represented in lower copy numbers (1 to 12 ) among the screened fragments. Out of $20 \mathrm{PD}$ accessions, seven showed profile A in all inserts tested. In 11 accessions, two profiles were present. Profile A dominated (198 of 220) but six new patterns were observed represented by 22 clones and designated B, C, D, H, K, and L. In two accessions, three different profiles were observed. In the first accession, profile A dominated again but two new patterns I and $\mathrm{J}$ appeared, represented in one or two copies, respectively. In the second accession, three new profiles were apparent, designated F (14 out of 20), E (5 out of 20), and G (1 out of 20).

Sequence analyses of $\boldsymbol{h} \boldsymbol{f l B}$ genes. The nucleic acid homology among the Belarusian $h f l B$ gene fragments of ' $C a$. P. mali' ranged
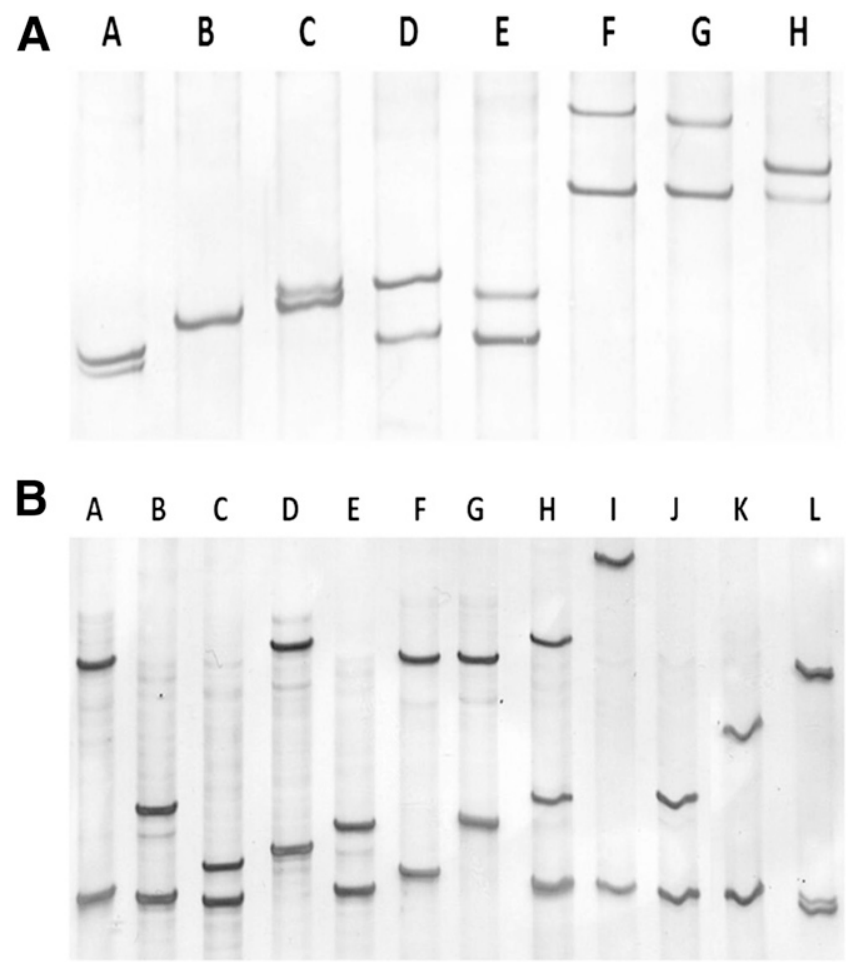

Fig. 1. SSCP profiles of PCR-amplified cloned $h f l B$ gene fragments of ' $C a$. P. mali' (A) and 'Ca. P. pyri' (B) strains from Belarus. 
between 95.4 and $100.0 \%$, while the amino acid sequences homology was slightly higher and varied from 97.7 to $100.0 \%$. In a pairwise comparison of the protein sequences, not more than four amino acid substitutions occurred between any of the analyzed sequences. Differences on the nucleic acid level represented most often silent mutations. The nucleic acid identity of the Belarusian $h f l B$ gene fragments and homologous ' $\mathrm{Ca}$. P. mali' sequences available in the database ranged between 94.3 and $100.0 \%$. The comparison showed that the sequence represented by profile C (accession no. LT548596), the most common among accessions from Belarus, shared $100.0 \%$ of nucleic acid identity with ' $\mathrm{Ca}$. P. mali' strains PM4, 3-1, and 3-6 from
Germany (accession nos. FM201249, HE819343, and HE819347, respectively). Cluster analysis of the nucleic acid sequences revealed that ' $\mathrm{Ca}$. P. mali' strains grouped together and formed two subclades within the cluster of apple proliferation strains (Fig. 2A) that revealed the heterogeneity already shown by sequence comparison. One group with $99 \%$ bootstrap support was formed by the identical sequences of six isolates represented by profile $\mathrm{C}$. The other isolates grouped together, with some variability within the subcluster, and represented by seven others SSCP profiles.

The nucleic acid homology of the $h f l B$ gene of ' $C a$. P. pyri' accessions from Belarus ranged from 81.3 to $100.0 \%$. The identity to
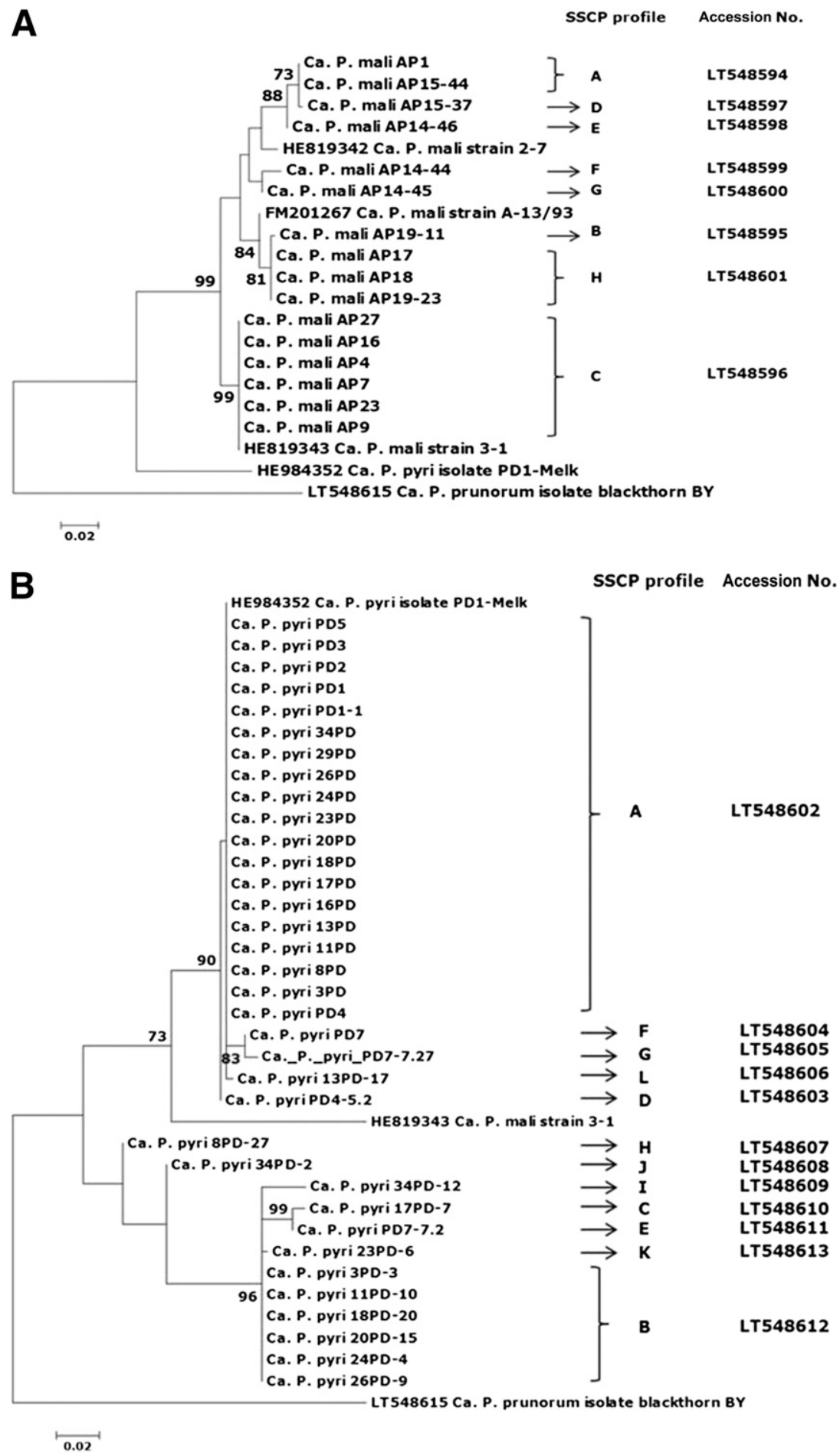

Fig. 2. Maximum likelihood analysis showing predicted relationships of 'Ca. P. mali' (A) and 'Ca. P. pyri' (B) strains based on the nucleotide sequences of $h f l B$ gene fragments. Numbers represent bootstrap values out of 1,000 replicates. Bootstrap values lower than $70 \%$ are not shown. The scale shows substitutions/site. 
'Ca. P. pyri' $h f l B$ gene sequences in the database ranged between 77.5 and $100.0 \%$. A pairwise comparison showed that sequences of profile $\mathrm{A}$ (accession no. LT548602), the most common among ' $\mathrm{Ca}$. P. pyri' accessions from Belarus, were identical to ' $\mathrm{Ca}$. P. pyri' strain PD1-Melk from Belgium (accession no. HE984352). The nucleic acid identity among ' $\mathrm{C} a$. P. pyri' from this study and ' $\mathrm{Ca}$. P. mali' ranged from 83.0 to $91.6 \%$. Phylogenetic analysis separated the Belarusian strains of ' $\mathrm{Ca}$. P. pyri' and formed two distinct clusters (Fig. 2B). One cluster was represented by the most common pattern A and patterns D, F, G, and $\mathrm{L}$. The nucleic acid identity among these sequences ranged from 98.2 to $100.0 \%$. The second cluster was formed by the less frequently occurring strains with patterns B, C, E, H, J, I, and K. The sequence identity within this cluster varied from 94.7 to $100.0 \%$. The identity between the isolates from the two clusters ranged from 88.3 to $94.9 \%$. Sequences assigned to the first cluster were more related to ' $\mathrm{Ca}$. $\mathrm{P}$. mali' than to ' $C a$. P. pyri' accessions that formed the second cluster. The amino acid sequences of ' $\mathrm{Ca}$. P. pyri' strains from the first cluster were identical. A pairwise comparison with sequences from the second cluster revealed differences in not more than nine positions in between any of the partners. The difference among the protein sequences from the two clusters was maximum 17 amino acid substitutions.

\section{Discussion}

This survey shows for the first time the presence of ' $\mathrm{Ca}$. P. mali' and ' $\mathrm{Ca}$. P. pyri' in apple and pear trees in Belarus using molecular techniques. The numbers for apple and pear trees examined is not representative for the country but an infection rate of $85.2 \%$ for apple trees and $79.3 \%$ for pear trees of 85 samples is significant and was unexpected. It can be assumed that the situation in other pome fruit growing areas is the same, but a country-wide screening will be necessary to finally assess the infection status and initiate management strategies. Because phytoplasma-resistant cultivars and rootstocks are not available, disease management is limited to vector control and phytosanitary measures. Control of the vectors is the most important measure against the spread of phytoplasmas when the diseases are already present but there is insufficient information on the occurrence of psyllid vectors in Belarus and about the effectiveness of national standard insecticide programs. The removal of potential pathogen reservoirs and the use of certified clean propagation material is particularly important in and around propagation facilities. Because ' $\mathrm{Ca}$. P. mali' and ' $\mathrm{Ca}$. P. pyri' are also transmitted by infected rootstocks, scions, and tissue culture, the use of certified material is mandatory to prevent phytoplasma spread. Therefore, nuclear stocks should be screened at regular intervals using PCR procedures. Even though ' $\mathrm{Ca}$. P. mali' and ' $\mathrm{Ca}$. P. pyri' are EPPO-listed quarantine pests, they are not included in the national list of quarantine pathogens of Belarus.

PCR technology is the method of choice for phytoplasma detection in terms of specificity as symptoms similar to AP and PD can be caused by other factors (Seemüller et al. 2011a). The nonobservance of specific disease symptoms might also be because plant inspection employees are not aware of the diseases and are untrained. The new knowledge on the presence of the pathogens in Belarus will hopefully raise the awareness of the authorities on this issue. The second focus of the study was aimed to describe the variability of ' $\mathrm{Ca}$. P. mali' and ' $\mathrm{Ca}$. P. pyri' strains in Belarus. Several nonribosomal genes, like $a c e F$, imp, pnp, sec $Y$, and $h f l B$, have been described suitable for studying intraspecific variations (Danet et al. 2007; Schneider and Seemüller 2009). Of those, the largest number of sequence information is available for the $h f l B$ gene homolog ATP00464 of ' $C a$. P. mali' strains (Schneider and Seemüller 2009; Seemüller et al. 2011b). Therefore, a representative number of Belarusian apple and pear tree phytoplasma accessions were selected and the gene amplified by specific primers. The variability of $h f l B$ gene fragments was initially demonstrated by SSCP analysis and later confirmed by sequencing. With the SSCP technique, eight different profiles for ' $\mathrm{Ca}$. P. mali' and 12 different profiles for ' $\mathrm{Ca}$. P. pyri' were revealed. At least for ' $\mathrm{Ca}$. P. mali,' the variation is in agreement with results described by Schneider and Seemüller (2009), where a total of 20 different $h f l B$ SSCP patterns were obtained from $42^{\prime} \mathrm{Ca}$. P. mali' accessions.
The analysis further revealed the presence of multiple infections in some apple and pear trees with up to three distinct phytoplasma strains. Interestingly, the rate of multiple infections was higher for pear trees, as out of 20 PD accessions, 11 accessions revealed two profiles and two accessions showed three distinct profiles, while of 12 AP accessions, only three accessions had more than one profile. It is very likely that the complexity of the phytoplasma population in Belarusian apple and pear trees is even higher than reported here. Although the total number of cloned PCR fragments screened was significant, the number per accession was low. Therefore, strains present in low numbers will only be detected in larger screenings. The occurrence of multiple strains in AP infected apple trees was first demonstrated by Seemüller et al. (2010). Sequences of the $h f l B$ gene fragments of ' $\mathrm{Ca}$. P. mali' and ' $\mathrm{Ca}$. P. pyri' isolates from Belarus revealed a high level of variability. Multiple alignment of sequenced fragments showed that those having the same SSCP profiles shared identical nucleotide sequences. No clear correlation between a certain mutation and a specific SSCP profile could be established. Even one base pair in difference was sufficient to generate a different profile. Cluster analysis of the studied isolates and those publicly available revealed that the $h f l B$ gene sequences of Belarusian ' $C a$. P. mali' isolates were related to other ' $\mathrm{Ca}$. P. mali' strains and distinct from other phytoplasma species of the apple proliferation group. Interestingly, that Belarusian ' $\mathrm{Ca}$. $\mathrm{P}$. pyri' isolates formed two clusters and accessions from the first cluster were more related to ' $\mathrm{Ca}$. P. mali' than to ' $C a$. P. pyri' sequences assigned to the second cluster. The separate clustering of the $h f l B$ gene clones is unclear, but hypothetically might be a result of homologous recombination during the pathogen evolution. Characterization of more isolates is needed to clarify the background of the phenomenon. Considering the small number of samples examined and the fact that they came from a narrow region, a high diversity of $h f l B$ gene for the apple proliferation group phytoplasmas can be postulated. Seemüller et al. (2013) demonstrated that ' $\mathrm{Ca}$. P. mali' strains clustered in phylogenetic analysis based on the $h f l B$ gene according to their virulence and identified amino acids markers related to virulence. Therefore, the knowledge of the strain composition is of pathological relevance. For the pear decline phytoplasma, no information is available on strain variability in populations. Therefore, the population complexity in the Belarusian accessions cannot be compared with the situation elsewhere. The new finding of phytoplasma-infected Belarusian trees and the presence of multiple strains needs to be examined over a longer period to confirm the correlation established by Seemüller et al. (2013).

This study confirms for the first time the presence of ' $\mathrm{Ca}$. P. mali' in apple and ' $\mathrm{Ca}$. P. pyri' in pear trees in Belarus and also demonstrates strain variability and multiple infection of the trees. This work will form the basis for further studies in Belarus to assess the occurrence of pome fruit tree phytoplasmas in the country, to study their molecular diversity, and the pathological relevance of particular populations.

\section{Acknowledgments}

This study was supported by the Alexander von Humboldt Foundation via Georg Forster Research Fellowship (HERMES) for postdoctoral researchers. The authors would like to thank Z. Kozlovskaya, the Head of the Department of Fruit Breeding, and O. Yakimovich, the researcher of the department, for providing pear samples from Belarus.

\section{Literature Cited}

Ahrens, U., and Seemüller, E. 1992. Detection of DNA of plant pathogenic mycoplasmalike organisms by a polymerase chain reaction that amplifies a sequence of the 16S rRNA gene. Phytopathology 82:828-832.

Bertaccini, A., and Duduk, B. 2009. Phytoplasma and phytoplasma diseases: a review of recent research. Phytopathol. Mediterr. 48:355-378.

Cieślińska, M., and Kruczyńska, D. E. 2014. Detection and molecular characterization of phytoplasmas infecting apple trees in Poland. Hortic. Sci. (Prague) 41:27-33.

Cieślińska, M., and Morgas, H. 2011. Detection and identification of Candidatus Phytoplasma prunorum, Candidatus Phytoplasma mali and Candidatus Phytoplasma pyri in stone fruit trees in Poland. J. Phytopathol. 159:217-222.

Danet, J. L., Bonnet, P., Jarausch, W., Carraro, L., Skoric, D., Labonne, G., and Foissac, X. 2007. Imp and secY, two new markers for MLST (multilocus 
sequence typing) in the $16 \mathrm{SrX}$ phytoplasma taxonomic group. Bull. Insectol. 60:339-340.

Delic, D. 2012. Polymerase chain reaction for phytoplasmas detection. Pages 91-118 in: Polymerase Chain Reaction. P. Hernandez-Rodriguez and A. P. Ramirez Gomez, eds. InTech, Rijeka, Croatia.

Girsova, N., Bottner, K. D., Mozhaeva, K. A., Kastalyeva, T. B., Owens, R. A., and Lee, I.-M. 2008. Molecular detection and identification of group 16SrI and 16SrXII phytoplasmas associated with diseased potatoes in Russia. Plant Dis. 92:654.

Gundersen, D. E., and Lee, I.-M. 1996. Ultrasensitive detection of phytoplasmas by nested-PCR assays using two universal primer pairs. Phytopathol. Mediterr. 35:144-151.

IRPCM Phytoplasma/Spiroplasma Working Team - Phytoplasma taxonomy group. 2004. 'Candidatus Phytoplasma,' a taxon for the wall-less, non-helical prokaryotes that colonize plant phloem and insects. Int. J. Syst. Evol. Microbiol. 54:1243-1255.

Jomantiene, R., Valiunas, D., Ivanauskas, A., Urbanaviciene, L., Staniulis, J., and Davis, R. E. 2011. Larch is a new host for a group 16SrI, subgroup B phytoplasma in Ukraine. B. Insectol. 64:S101-S102.

Kukharchik, N. V. 2012. Virus and Phytoplasma Diseases of Fruit and Berry Crops in Belarus. Belaruskaja Navuka, Minsk, Belarus.

Lee, I.-M., Davis, R. E., and Gundersen-Rindal, D. E. 2000. Phytoplasma: phytopathogenic mollicutes. Annu. Rev. Microbiol. 54:221-255.

Lee, I. M., Gundersen, D. E., Hammond, R. W., and Davis, R. E. 1994. Use of mycoplasmalike organism (MLO) group-specific oligonucleotide primers for nested-PCR assays to detect mixed- MLO infections in a single host plant. Phytopathology 84:559-566.

Lorenz, K. H., Schneider, B., Ahrens, U., and Seemuller, E. 1995. Detection of the apple proliferation and pear decline phytoplasmas by PCR amplification of ribosomal and non-ribosomal DNA. Phytopathology 85:771-776.

Mehle, N., Ambrozic Turk, B., Brzin, J., Nicolic, P., Dermastia, M., Boben, J., and Ravnikar, M. 2010. Diagnostics of fruit trees phytoplasmas - the importance of latent infections. Julius-Kuhn-Archiv 427:412-414.

Musić, M. S., Krajačić, M., and Škorić, D. 2008. The use of SSCP analysis in the assessment of phytoplasma gene variability. J. Microbiol. Methods 73:69-72.
Schneider, B., and Seemüller, E. 2009. Strain differentiation of 'Candidatus Phytoplasma mali' by SSCP and sequence analyses of the $h f l B$ gene. J. Plant Pathol. 91:103-112.

Seemüller, E., Carraro, L., Jarausch, W., and Schneider, B. 2011a. Apple proliferation phytoplasma. Pages 67-73 in: Virus and Virus-like Diseases of Pome and Stone Fruits. A. Hadidi, M. Barba, T. Candresse, and W. Jelkmann, eds. APS Press, St. Paul, MN.

Seemüller, E., Kampmann, M., Kiss, E., and Schneider, B. 2011b. HflB gene-based phytopathogenic classification of 'Candidatus Phytoplasma mali' strains and evidence that strain composition determines virulence in multiply infected apple trees. Mol. Plant-Microbe Interact. 24:1258-1266.

Seemüller, E., Kiss, E., Sandor, S., and Schneider, B. 2010. Multiple infection of apple trees by distinct strains of 'Candidatus Phytoplasma mali' and its pathological relevance. Phytopathology 100:863-870.

Seemüller, E., Kunze, L., and Schaper, U. 1984. Colonization behavior of MLO, and symptom expression of proliferation-diseased apple trees and declinediseased pear trees over a period of several years. J. Plant Dis. Prot. 91:525-532.

Seemüller, E., and Schneider, B. 2004. 'Candidatus Phytoplasma mali', 'Candidatus Phytoplasma pyri' and 'Candidatus Phytoplasma prunorum', the causal agents of apple proliferation, pear decline and European stone fruit yellows, respectively. Int. J. Syst. Evol. Microbiol. 54:1217-1226.

Seemüller, E., Sule, S., Kube, M., Jelkmann, W., and Schneider, B. 2013. The AAA+ ATPases and HflB/FtsH proteases of 'Candidatus Phytoplasma mali': phylogenetic diversity, membrane topology, and relationship to strain virulence. Mol. Plant-Microbe Interact. 26:367-376.

Smart, C. D., Schneider, B., Blomquist, C. L., Guerra, L. J., Harrison, N. A. Ahrens, U., and Kirkpatrick, B. C. 1996. Phytoplasma-specific PCR primers based on sequences of the 16S-23S rRNA spacer region. Appl. Environ. Microbiol. 62:2988-2993.

Tamura, K., Stecher, G., Peterson, D., Filipski, A., and Kumar, S. 2013. MEGA6: Molecular Evolutionary Genetics Analysis version 6.0. Mol. Biol. Evol. 30: 2725-2729.

Valiunas, D. 2003. Identification of Phytoplasmas in Lithuania and Estimation of Their Biodiversity and Molecular Evolutionary Relationships. Ph.D. Thesis, Institute of Botany and Vilnius University, Vilnius, Lithuania. 